\title{
The Hindrance of Moral Emotions: Using Leader Role Modeling to Foster Morally Courageous Behavior in Employees
}

\author{
Shahid Ullah ${ }^{*}$, Barkat Ullah Khan ${ }^{1}$, Muhammad Jawad Malik ${ }^{2}$ \\ ${ }^{1}$ School of Public Affairs, University of Science and Technology of China, Hefei, China \\ ${ }^{2}$ Department of Business Administration, School of Management, University of Science and Technology of China, Hefei, China \\ Email: *shahid@mail.ustc.edu.cn
}

How to cite this paper: Ullah, S., Khan, B. U., \& Malik, M. J. (2021). The Hindrance of Moral Emotions: Using Leader Role Modeling to Foster Morally Courageous Behavior in Employees. Open Journal of Social Sciences, 9, 429-450.

https://doi.org/10.4236/jss.2021.96030

Received: May 27, 2021

Accepted: June 27, 2021

Published: June 30, 2021

Copyright $\odot 2021$ by author(s) and Scientific Research Publishing Inc. This work is licensed under the Creative Commons Attribution International License (CC BY 4.0).

http://creativecommons.org/licenses/by/4.0/ (c) (i) Open Access

\begin{abstract}
The study is conducted with an aim to assess the impacts of leader ethical role modeling and leader safety role modeling on the morally courageous behavior among employees. The study has also checked the mediation of moral emotions, including moral sympathy, moral contempt and moral anger and disgust in between the relationship of leader ethical role modeling and morally courageous behavior among employees, and also between the relationship of leader safety role modeling and morally courageous behavior among employees. Quantitative data is collected from 364 employees, supervisors that are working together at the workplace and have high interaction and social exchange relationships. Data analysis by applying SPSS and Amos has revealed significant and positive impact of leader safety role modeling on the morally courageous behavior among employees, whereas the impact of leader ethical role modeling is found to be insignificant. The mediation of moral sympathy, moral contempt and moral anger and disgust in the relationship between leader ethical role modeling and morally courageous behavior, and also between the relationship of leader safety role modeling and morally courageous behavior is found to be significant and positive. The research has expanded the literature by considering moral emotions for developing the morally courageous behavior in the employees and to maximize the organizational outcomes as well.
\end{abstract}

\section{Keywords}

Hindrance, Moral Emotions, Leader Role Modeling, Morally Courageous Behavior in Employees

\section{Introduction}

A morally courageous behavior among employees is very important as they help 
to create hindrances in the creating the misconducts in the organizations thus affecting the performance and stakeholders connected with the organization. In recent years to tackle the organizational misconducts has been very widely studied by scholars to know about the strategies to deal with the issues or problem (Ogunfowora, 2014). As the moral emotions of the employees working in an organization are a source of hindrance in the workplace as mostly the people who are going through any kind of moral emotional forms such as anger, sympathy, contempt, and disgust are more likely to exhibit the morally courageous behavior (Koerner, 2014) explaining the courageous behavior in terms that the organization shapes the employee's identities by providing them with the healthy and creative environment to work on. Before that, workplace courage helps to shape the courageous identities of the individuals. Courageous acts in the organization can help to change people behaviors and attitude relating to unethical acts or conducts. Courage involves saving the interest of the people in a workplace by taking the risks of showing courageous behavior. As the organization is the entity that had to live the life of survival due to high competition in the market and for its efforts to survive is largely dependent upon how the employee's performance. Moreover, some persons get motivation from the workplace to build their characters and in response show different behaviours (Hulin, 2002). The effective performance and the behaviours of the employees are largely dependent upon the positive supervisory behaviours, which means that that the leader or supervisors behaviour cast a positive impact on the person personality and his behaviour (Liu, Liao, \& Loi, 2012). In an organization, moral emotions are very important for working as according to (Scott, 2001) moral emotions are the emotions that shape the person action but play an important part in moral judgement. Moral emotions are triggered in an employee while working in the organization when he perceives to be left out. The employee itself perceives that a certain action or event in an organization is undermining his or her interests. Therefore, to deal with the moral emotions of employees in an organization is a hot topic. There are certain forms of moral emotions that are evoked in an employee because of certain situations. These emotions can be related to various work-related experiences as the employee had been encountered with the bad behaviour, no timely payment of the salary or on the other side the helping behaviour can trigger the moral emotions. Whereas the former behaviours from the organization's side or supervisor side can evoke Anger and contempt, on the other hand later work-related experiences can promote the behaviour of gratitude, admiration etc. (De Jong, Clinton, Rigotti, \& Bernhard-Oettel, 2012). However, the emotion can be positive and negative as most of the employees who came across negative situations or work-related experience show negative moral emotions. Based on these moral emotions the behaviour is also affected by the employees as they show the destructive behaviour that affects the organization performance ultimately. The destructive behaviours are bullying, bad behaviour from the supervisor or leader side named as deviant behaviours that are seen in the whole world. As the factors which lead towards deviance are eco- 
nomic stress, less job pleasure, discrimination, working issue \& workers view (Nasir \& Bashir, 2012). To develop a morally courageous behaviour among the employees to raise their voices against the moral emotions that they face in the organization because of the work experiences of both types positive and negative. The ethical role of the leader or a supervisor is needed in this regard so that the employees may not indulge in negative behaviours thus affecting the organization's performance. As ethical leadership is the type of leadership "the demonstration of normatively appropriate conduct through personal actions and interpersonal relationships, and the promotion of such conduct to followers through two-way communication, reinforcement, and decision-making" (Brown et al., 2005: p. 120). In other terms, the leader in an organization who acts as a role modeller must present his ethical role in dealing with the employees so that employee may be able to exhibit morally courageous behaviour in which they have to be prepared for everything or situation to deal with. Because engaging in courageous behaviour can lead to threats and risks. However, many studies have been conducted in the past to study how the leader help to develop morally courageous behaviour among employees as it is considered a challenge for the leaders. A study by (Ogunfowora, Maerz, \& Varty, 2021), studied how leaders foster morally courageous behaviour in the employees through their ethical role model containing some limitation only studying the ethical leader role. Moreover, other aspects related to the leaders can also be explored in creating moral courage behaviour. On the other hand, a study by (Harvey et al., 2016) relating to justifying the deviant behaviour among employees through moral emotions and attribution had also provided the gap of leader's ethical role in minimising the moral emotions that are on the side of the organization mostly anger, contempt, disgust etc. In another study moral emotions were categorized into negative and positive moral emotions in which negative moral emotions of the employees are towards the organization in which organization where violates the standards and obligations. Whereas positive emotions are depicted by the employees if they experience good behaviour ethical conduct from the side of the organization. However, the positive moral emotion can be towards the other employees who have been harmed from the negative moral emotions by the organizations (Ford et al., 2017). Another study relating to moral emotions and ethics in an organization studied or explained the importance of ethics and moral emotions and what role is played by these emotions in an organization regarding the special issue. Thus, the study had provided insights into moral emotions and ethics but neglected the leader role modelling (Gabriel, Lindebaum, \& Geddes, 2016). Another study by (Syed et al., 2019) studied the negative role of a leader and its effect on moral emotions and bullying behaviour among employees. The study explained what the effect on employee behaviour is if the leader is, morally corrupt So based upon the gaps defined in the previous studies the present study is going to explain how the hindrances of moral emotions can be controlled through the leader role modelling thus developing morally courageous behaviour among employees. As in the previous studies, the positive and the negative 
moral emotions are categorized and their effect on the employee's behaviour is discussed but, in this study, considering the leader role model in creating courageous behaviour thus by considering how the moral emotions together with the leader role encourage the employees to exhibit courageous behaviour against the negative emotions.

The research paper consists of an introduction and the literature review section which have been reviewed for the developed theoretical model and hypothesis development which are tested by collecting data by following the specific research methodology for measuring the impact or influence of the variables by applying data analysis techniques. After that, the results are discussed in detail and based on the results limitation and future direction are also presented in the last that are to be considered by the prospective researchers in the future.

\section{Literature Review}

\subsection{Theoretical Background}

Social learning theory provides the theoretical background to the study as it was introduced by (Bandura, 1997). The study of creating or fostering morally courageous behaviour is supported by this theory as a person or individual learns from the behaviour of the idles who they admire and follow and, on that basis, they act based on the behaviours. Social learning is the process of learning through the role models without taking the risk of the direct learning that may lead towards the various issues or problems. The process is related to the work and observes the behaviour of the role model and then stores it in your memory and then after storing performing the learned behaviour in a different setting by drawing courage and motivation. The leader role model in an organization is very important as it is the central influential figure of the organization whose behaviours are explicitly seen or observed by the employees. These leaders are copied by their followers or employees because the behaviour performed by them is perceived as very credible. The interactions among the leader or employees are ample because the leader sets the standards, monitors the performance, and provide feedback on the works performance and the behaviour modelling (Ogunfowora, 2014). Based on the above theory or learning process it is likely to observe that the leaders tend to foster the behaviour among the employees. Based on this theoretical ground the leader's role modelling help to create morally courageous behaviour. By examining the mediating role of the moral emotions such as sympathy, anger, contempt, disgust between the leader role modelling and morally courageous behaviour and leader safety role modelling, respectively.

\subsubsection{Hypothesis Development}

1) Leader Ethical Role Modelling (LERM) and Morally Courageous Behaviour (MCB)

A leader in an organization helps to create a good organizational life so, ethi- 
cal leadership is very efficient in dealing with deviant behaviour According to Social Learning Theory (Bandura, 1997), a leader affects subordinates as he is a role model that moderates the attitudes of the behaviours of people through behaving ethically and the subordinates follow him by learning and observing as (Bandura, 1997), had also explained that the followers try to copy the conduct of their leaders they tend to learn from their leaders as they act as a model for them to be followed so they must be exchanged in the ethical conducts, as a leader they are used to get the others punished and rewarded based on their unethical behaviours. The leader role is under the leadership theories the person adopts in the organization such as transformational, leadership, servant, ethical, leadership. All these theories have a different impact on the follower's perception of exhibiting the behaviour Role modelling of the leaders depends upon how the followers or leaders interact at the workplace. The leader serves as a role model in the organization by presenting examples of persistence, optimism, hope and integrity (Brown et al., 2005). Moreover, the leader's role in developing courageous behaviour had been thoroughly explained by the social learning theory. A moral courage individual is a person who takes risk for the rights of the people around. As the behaviour is exhibited by the employees to raise voice and stand against the whistleblowing issues, unethical and illegal misconducts by the organization (Detert \& Bruno, 2017). Various studies have been conducted in which the leader's role modelling had been studied in detail to create the specific behaviours among employees as a study by (Ogunfowora, Maerz, \& Varty, 2021) to create morally courageous behaviour among employees studies the ethical role of leader in fostering courageous behaviour. Because the employees perceive or follow the role model as an example and thus replicate the behaviours performed by the leader therefore in their work considering it credible. As this study explains that the leader ethical role modelling positively fosters moral courageous behaviour (MCB). However, many studies have also been conducted to study the role of ethical leadership in making employees to least likely to engage in the destructive behaviours for the organization which means the ethical role of leadership in terms that if they behave ethically will lead the employees to least likely be engaged in the deviant behaviours (Yasir \& Rasli, 2018). So based upon the above literature review and the studies gone through the proposed hypothesis is as follow

$\mathrm{H} 1:$ Leader ethical role modelling is significantly related to morally courageous behaviour among employees.

2) Leader Safety Role Modelling (LSRM) and Morally Courageous Behaviour (MCB)

Workplace courage is different from morally courageous behaviour among employees at the workplace as workplace courage is the risky behaviour that is the behaviour not to deal with moral causes in the workplace. The workplace courage involves no interest of the employees just in that case if the employee goes against the supervisory decision of the leader and challenges him openly by staking his relationship with the figure, therefore (Detert \& Bruno, 2017). The 
key role of the leadership regarding the safety modelling is very much concerned as this is related with the concern that how the leaders behave safely or interact with the employees so that they may exhibit the same behaviour and the safety performance is increased thereof. However, this role of the leader encouraging safety is influenced by transformational leadership. Because people who are engaged in moral courage behaviour are more likely to be injured as they have more health and life threats. Different studies explained that morally courageous people are encountered with physical injuries, psychological issues of depression, anxiety and fear of being harmed, social injuries such as loss of the relationship among supervisor and the employee, economic injuries such as loss of the career, job, financial security etc. (Osswald et al., 2010). Therefore, the studies suggest that the people with the transformational leadership aspects in which the leaders follow the safety aspect in role modelling people experience low rates of injuries as discussed above. This means that the leader acts as a motivational role model for the employees because they follow his or her every practice in an organization so that he or she can get success in his career. As many studies suggest that leaders as role models in which the employees learn specific skills and behaviours from them (Morgenroth et al., 2015). The leader safety role modelling involves fostering the employee's safety performance thus encouraging safe participation from his side to take out the measures that will promote the safety of the employees in the work, thus, encouraging the employees to be involved in the safety participation to help the co-workers in promoting the safety measures at the workplace, furthermore, which means that if the leader will perform the behaviour of encouraging safety, measures and acting against the moral misconducts relating to the safety of employees then the employees will be encouraged to exhibit the moral behaviour, therefore. The behaviour of a leader or employee relating to the safety measures will be considered as an organisational citizenship behaviour in many studies. The study by (Clarke \& Ward, 2006) which have explained the role of soft leadership tactics in encouraging the employees' participation in safety have demonstrated that the safety role of the leaders is positive in encouraging safety participation behaviour among employees. Another study relating to the leader-member exchange relationship and development of the constructive safety behaviour among employees have demonstrated that if the same behaviours are exchanged between the leader and members such as if the leader is showing the safety concern for the employees and advance voice in case any moral misconduct relating to safety. Then this behaviour will be as same executed by the followers for his or her co-worker in the workplace.

So based upon the studying of the relevant literature it has been proposed that if the leaders play a safety role model for the employees or followers the employees are more likely to engage in morally courageous behaviour for promoting safety. Based upon the above finding and gaps identified the proposed hypothesis is as follow.

H2: Leader safety role modelling is significantly related to morally cou- 
rageous behaviours among employees.

3) The Mediating Role of the Moral Emotions between Leaders Ethical Role Modelling and Morally Courageous Behaviour among Employees

Moral emotions are of a wide and interesting topic these days as the organizations are the social entities $s$ in which the employees are diverse who work together to achieve the common goal of the organization without infringing the rights of one another through the moral misconducts. Emotions are the factor that let the employees work together or socially interact. However, moral emotions are the emotions that are particularly there to endorse the moral standards made by society (Haidt, 2003). Moreover, the moral emotions in an organisation are therefore defined as a thing that helps to avoid misconducts or behaviours that are not aligned with society moral standards. Moral emotions help to elevate prosocial behaviour among employees. These emotions are learned from past experiences, learning, and biologically. People mostly experience emotions when they face any kind of mistreatment or misbehaving from the other individual. These emotions help people to prepare themselves or protect themselves from the upcoming situations and how to deal with them courageously (Greenbaum et al., 2019). Moral emotions such as sympathy, contempt, anger, and disgust are presented in this study to find how these emotions mediate the relationship between leader ethical role modelling and morally courageous behaviour

4) Mediating Role of the Moral Sympathy (MS), Moral Contempt (MC) and Moral Anger and Disgust (MAD)

Morality is composed of the systems of norms and the prescriptions and ethical standards that prevent harm to others. Sympathy is the positive moral emotion that includes showing care and concerns for other people emotions and situations generally. Emotions are related to the psychology of an individual (MAIBOM, 2009). The moral emotions are agent-driven or recipient driven as explained by a study for studying moral emotions as implications for employee's behaviour. As the agent-driven means the moral emotions that are because of the mistreatment encountered by the employees at the workplace from the side of the organization so the moral emotions of anger, contempt and disgust are evoked in the employees. Whereas sympathy is the emotions that are recipient driven which means that is triggered in an individual because of the harm to the wellbeing and interest of other employees. The persons feel his situation and feel his pain and show sympathy for him or her, therefore. This is the positive moral emotion towards the recipient (employee) (Ford et al., 2017). The leader ethical role modelling relating to the sympathy for the employee's problem will yield or evoke a positive moral emotion of sympathy and thus it will give courage to the employees to show morally courageous behaviour against the misconduct encountered by the employee.

Moreover, explaining the negative moral emotions either would help the employees to show morally courageous behaviour or not. The next moral emotion is Contempt a negative moral emotion that is evoked in an individual if he or she feels left out or worthless in an organization by the agent (organization). 
Furthermore, in any other case of the other employee who had been treated disrespectfully and this thing is considered by the third person. So, this negative moral emotion of contempt is experienced by the employee who feels that the efforts of the employees are not valued in the organization (Haidt, 2003). In that case, the leadership styles or behaviours are important in modelling the behaviour of the employee as they became a source of evoking moral emotions among employees. So the ethical leader role of the leader towards protecting their follower's or employees emotions will help the other employees behave courageously by showing moral concerns for their fellows (Tse et al., 2018).

When employees treated unfairly by their leaders it will generate negative emotions among them such as anger, disgust which is the result of the corrupt leadership they will perform deviant behaviour and in return will also treat their peers negatively. So an effective leadership or ethical role modelling of a leader will help the employees to deal with the negative emotions very effectively (Syed et al., 2019). Thus, it will prepare the employees to behave courageously against the negative emotions of anger and disgust as anger is the feeling of displeasure having the varying adverse list of destructive consequences such as violence, aggression, bullying. A study by (Lindebaum \& Geddes, 2016) had studied the role of moral anger as a moral emotion in organisational behaviour studies how moral anger affects the organization and employee's behaviour. Disgust is the lowest negative moral emotions that fall below the morality standards. It means that protecting the individual from the feeling of fear and helplessness that the person cannot do anything and his or her career is finished etc. So, in that case empowering your employees through ethical role modelling can help the employees to deal with disgust moral emotion efficiently and effectively by showing morally courageous behaviour (Stange, 2019).

H3: Moral sympathy significantly mediates the relationship between leader ethical role modelling and morally courageous behaviour (MCB).

H4: Moral contempt significantly mediates the relationship between leader ethical role modelling and morally courageous behaviour (MCB).

H5: Moral Anger and disgust significantly mediates the relationship between leader ethical role modelling and morally courageous behaviour $(M C B)$.

5) The Mediating Role of the Moral Emotions between Leader Safety Role Modelling and Morally Courageous Behaviour among Employees

Social exchange theory is dependent upon the leader-member exchange theory in which the social interactions occur between two parties such as it may be between employee or supervisor, employee and employee, employee and organization (Blau, 1964). As the relationship based on the social exchange theory is reciprocal so the employees demand supervisory support to carry out their work in the workplace moreover the employee's needs safety of the work. On the other side, the supervisor needs compliance with the safety rules and standards made by the organizations to ensure workplace safety (Huang et al., 2016). The supervisor or subordinate relationship is very crucial in creating a safe climate at 
the workplace. Several scholars who have worked on the safety climate in organizations have demonstrated that the social exchange theory perspective can be used to identify the organizational factors that will help to create the safety climate. Moreover, how the safety climate improves the quality of relationship among the supervisor and employee and the quality of relationship identifies the workplace safety behaviours among employees. The workplace safety behaviour demands employees to actively take part in safety-related activities so that to avoid the decisions that may affect the safety climate (Zohar, Huang, Lee, \& Robertson, 2014). Since the strong quality of the exchange relationship among the employee and leader will create the employee empowerment so that they can show the voice concerns relating to safety issues. The leader role modelling relating to the safety of the employees in an organization will prove very beneficial because it will lead towards a high-quality exchange relationship among them. Therefore, it means if the leader exhibits the voice behaviour to promote the employee's safety then ultimately the employee will have the courage to show the behaviour to speak courageously against the unsafe practices at the workplace (Huang et al., 2021). The morally courageous behaviour is empowered in the employees if they get the proper role modelling from the side of the leader. So, the moral emotions can also help to develop courageous behaviour among employees to raise a voice against unfair practices. Based upon the above findings the mediating role of the moral emotions is proposed in this study by presenting the following hypothesis:

H6: Moral sympathy significantly mediates the relationship between leader Safety role modelling and morally courageous behaviour (MCB).

H7: Moral Contempt significantly mediates the relationship between leader Safety role modelling and morally courageous behaviour (MCB).

H8: Moral Anger and disgust significantly mediates the relationship between leader Safety role modelling and morally courageous behaviour (MCB).

\subsubsection{Conceptual Model}

After the thorough review of the literature as discussed above in which the various author's point of views have been explained in alignment with our research question and research objectives of the study, and thus on that basis we are in the position to develop our conceptual research framework that you can see in Figure 1 we have the independent variable of the leader ethical role modelling and leader safety role modelling. On the other side the dependant variable of morally courageous behaviour among employees, thus, presenting the mediating variables of the moral emotions to find out the mediating role of moral emotion between ethical role modelling and morally courageous behaviour, leader safety role modelling and morally courageous behaviour among employees.

\section{Research Methodology}

\subsection{Population and Sampling}

The study is related to analysing the leader ethical role modelling and leader 


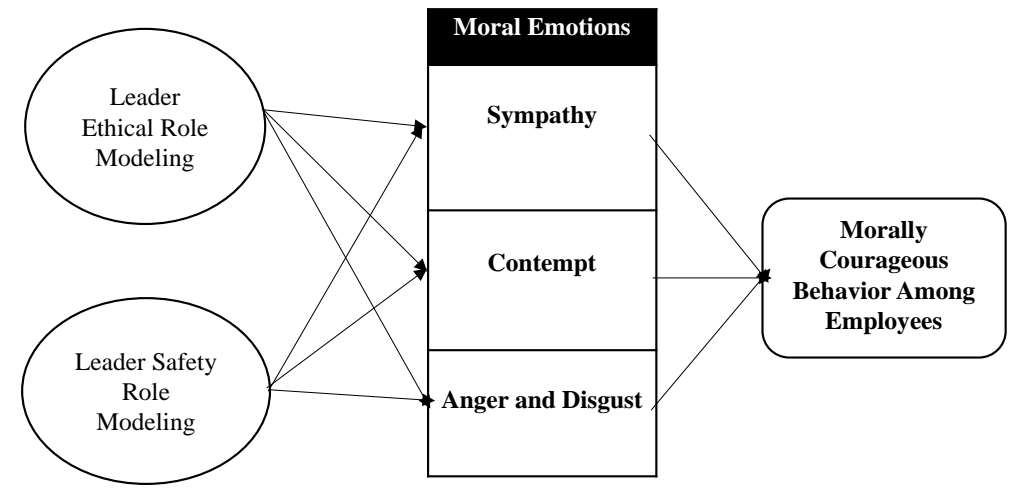

Figure 1. Theoretical framework.

safety role modelling in creating morally courageous behaviour among employees through the mediating role of the moral emotions. For that purpose, the population targeted to collect the data were the employees working in the organizations. Collecting the data from all the employees was difficult so the sample was selected to collect the data following the purposive sampling technique. More specifically the employees, supervisors who are working together at the workplace and have high interaction and social exchange relationship were selected. The sample size selected was based on the method of Joseph F. Hair et al. (2010) in which the sample size was 364 .

\subsection{Data Collection}

The data for the current study were collected by using the tool of the structured questionnaire consisting of the items. The questionnaire was distributed among the respondents through the online google doc. To record the responses a five-point Likert scale was used in which the respondents could rate their responses against specific questions ranging from 1 to 5 in which starting from strongly disagree to agree. The questionnaire was designed by adapting the scale of the researchers who have conducted similar studies in the past. The questionnaire validity was ensured by getting it approved by experienced researchers in the field. The data was collected from the respondents at a single point of time using the cross-sectional time horizon in which multiple responses were collected from the respondents at a specific time. Quantitative research method has been selected because of the flexibility for the methods of data analysis and presentation, this method is going to assist the researcher in analyzing the data utilizing different quantitative tools and techniques. Moreover, the specific tool of online Google document has been selected for the purpose of data collection because of the restrictions applied due to the pandemic of COVID-19, and also because of the restrictions of the lockdown as well.

\subsection{Measures}

To ensure the validity and reliability of the questionnaire scale were adapted from the previous studies for measuring the leader ethical role modelling a six 
items scale was adapted from the studies of the (Ogunfowora, Maerz, \& Varty, 2021) who studies how ethical role modelling creates morally courageous behaviour among employees in which the researchers have updated scale of the ethical role modelling by considering the 3 item scale used by the (Ogunfowora, 2014) and (Rich, 1997) that assess the supervisory role modelling. Moreover, to measure the leader safety role modelling six-item scale was also used which was also adapted from the leader role modelling studies of (Ogunfowora, Maerz, \& Varty, 2021). The sample questions items for measuring the leader ethical role were 1) My supervisor/manager exhibits the kind of ethical behaviour that I try to imitate. 2) My supervisor/manager provides a good model for me to follow concerning ethics. 3) My supervisor/manager acts as a role model for me concerning ethics. So, in total, 3 items were considered for this study, for the sake of significant relevance.

Further, more to measure the leader safety role modelling the items were 1) My supervisor/manager exhibits the kind of workplace safety behaviour that I try to imitate, 2) My supervisor/manager provides a good model for me to follow concerning workplace safety, 3) My supervisor/manager acts as a role model for me concerning workplace safety. So, in total 3 items were adopted from the scale for this variable as well. To study how these types of leader role modelling such as the ethical and safety role modelling help to foster courageous behaviour among employees. A scale to measure morally courageous behaviour was adapted consisting of the 5 items from the study of (Sekerka, Bagozzi, \& Charnigo, 2009) who have conceptualized and measured moral courage in case of the ethical challenges faced in the organization. In which the sample items were when an employee encounters an ethical challenge, he/she takes it on with moral action, regardless of how it may pose a negative impact on how others see him/her. To measure moral emotions such as sympathy a four-item scale was adapted from the study (Thornberg et al., 2016). For moral contempt, the scale was adapted from the studies of (Crowley, 2013) and (Steiger \& Reyna, 2016). Furthermore to measure moral anger and disgust the scale of the instrument was analysed from the studies of (Izard, Libero, Putnam, \& Haynes, 1993) in which the scales of the contempt anger and disgust were analysed or combined.

\subsection{Data Analysis}

The quantitative research method is followed as the study is related to the relationship testing Data analysis is done by applying the statistical techniques through the use of SPSS and AMOS. Whereas data entry and variable designing are done in the SPSS software. The following analysis is done by SPSS to check the accuracy of the questionnaire. Data screening is done to find out is there any missing value outlier (wrongly interpreted value, or normality). Demographic analysis is performed to check the frequency of the respondent's age, gender, experience, and qualification. On the other hand, AMOS is used for conducting a model fitness test to determine whether the sample data selected from popula- 
tion turns to a normal distribution. Confirmatory factor analysis in which the convergent validity and discriminant validity is measured for hypotheses testing and Partial Least Square and structural equation modelling is used to check the relationship, which will include the mediation or moderation analysis of the variables. The reason behind using the SEM through AMOS is that it provides the overall goodness of model fit and will help to eliminate errors through confirmatory factor analysis.

\section{Data Analysis and Interpretation}

\subsection{Demographical Details of the Respondents}

The respondents were 364 in total, out of which 165 respondents were female and 199 respondents were males, the age of the respondents has been divided into the equal intervals of 10 years, 117 respondents of the study were of the age below 25 years, 143 of the respondents of the study were of the age between 25 to 35 years, 89 of the respondents of the study were of between 35 to 45 years in age and the 15 respondents of the study were of the age below 45 years. As far as the qualifications of the respondents are considered, 48 of the respondents had their intermediate done, 157 of the respondents had the education level of graduation, 123 of the respondents had the master's level education and 36 of the respondents had some other higher or lower degree.

The descriptive statistics of this study have been provided in Table 1.

\subsection{Descriptive Statistics}

Descriptive statistics provide summary of the collected data, and also represent the level of normality of the data and show any kind of outliers that are present in the data, in the table above $\mathrm{N}$ is representing the total number of valid responses that are 364 . It has also been observed that the response values lie between the valid range of 1 and 5, that are the minimum and maximum values. This shows that the data lies in valid and normal range and there are no outliers present in the data. Moreover, the low values of standard deviation and skewness represent least dispersion and spread of the data, representing that the data is distributed in normal form.

\subsection{KMO and Bartlett's Test}

Kaiser-Meyer-Olkin Measure of Sampling Adequacy tests the significance and usefulness of the factor analysis, the ideal value for this factor is above 0.50 , and in this case, it can be observed that the resultant value is 0.928 , which is significantly higher than the ideal value, which represents the significance and validity of the factor analysis, it also represents usefulness of the factor analysis for this study. Moreover, the value of significance should be less than 0.05 , for the variables to be related and be significant as a model for the study, and in this case at df level 190, the value of significance is less than 0.05 , which shows the usefulness and significance of the model for the study (Table 2). 
Table 1. Descriptive statistics.

\begin{tabular}{|c|c|c|c|c|c|c|c|}
\hline & \multirow{2}{*}{$\begin{array}{c}\mathrm{N} \\
\text { Statistic }\end{array}$} & \multirow{2}{*}{$\begin{array}{c}\text { Minimum } \\
\text { Statistic }\end{array}$} & \multirow{2}{*}{$\begin{array}{c}\text { Maximum } \\
\text { Statistic }\end{array}$} & \multirow{2}{*}{$\begin{array}{c}\text { Mean } \\
\text { Statistic }\end{array}$} & \multirow{2}{*}{$\begin{array}{c}\text { Std. Deviation } \\
\text { Statistic }\end{array}$} & \multicolumn{2}{|c|}{ Skewness } \\
\hline & & & & & & Statistic & Std. Error \\
\hline LERM & 364 & 1.00 & 5.00 & 3.2747 & 1.05623 & -0.213 & 0.128 \\
\hline LSRM & 364 & 1.00 & 5.00 & 3.3462 & 1.00129 & -0.344 & 0.128 \\
\hline MS & 364 & 1.00 & 5.00 & 3.5762 & 1.11303 & -0.473 & 0.128 \\
\hline MC & 364 & 1.00 & 5.00 & 3.1548 & 1.17605 & -0.234 & 0.128 \\
\hline MAD & 364 & 1.00 & 5.00 & 3.3558 & 1.11795 & -0.396 & 0.128 \\
\hline MCB & 364 & 1.00 & 5.00 & 3.5560 & 1.17834 & -0.567 & 0.128 \\
\hline Valid N (listwise) & 364 & & & & & & \\
\hline
\end{tabular}

Table 2. KMO and Bartlett's test.

Kaiser-Meyer-Olkin Measure of Sampling Adequacy

Approx. Chi-Square

7531.845

Bartlett's Test of Sphericity

Df

190

Sig.

0.000

\subsection{Rotated Component Matrix}

Table 3 is representing all the six factors and related items, 0.7 is the level of loading that is recommended for significant factor loading, end in the table above it can be seen that all the indicators have level of factor loading more than 0.7 , which is why the model is acceptable. The factor loading of the indicator 1 is significantly acceptable and reliable for MCB1, MCB2, MCB3, MCB4 and MCB5, all of the factor loadings are above 0.7 and same can be seen in the case of other indicators as well. Moreover, no kind of cross loading can also be observed in the data in the rotated component matrix, so the data and the model are reliable for further testing.

\subsection{Convergent and Discriminant Validity}

Table 4 is representing the convergent and discriminant validity of the variables of the model, that have been selected for this study, both the discriminate and convergent validity represent subcategories of the construct validity and represent their impacts together. If one kind of validity is present and the other one is not, it will not be sufficient for the purpose of establishment of the construct validity, the convergent validity represents the measures of the constructs, that are supposed to be related theoretically and also in reality so that correspondence can be drawn in between the same constructs, whereas the discriminant validity represents the factors that are not supposed to be related to each other and are in fact not related as well. So, the discriminant validity provides the discrimination between factors or the variables. Composite reliability or $\mathrm{CR}$ and AVE represent convergent validity, the value for both of these is supposed to 
Table 3. Rotated component matrix.

\begin{tabular}{|c|c|c|c|c|c|c|}
\hline & \multicolumn{6}{|c|}{ Component } \\
\hline & 1 & 2 & 3 & 4 & 5 & 6 \\
\hline LERM1 & & & & 0.801 & & \\
\hline LERM2 & & & & 0.877 & & \\
\hline LERM3 & & & & 0.831 & & \\
\hline LSRM1 & & & & & 0.822 & \\
\hline LSRM2 & & & & & 0.811 & \\
\hline LSRM3 & & & & & 0.809 & \\
\hline MS1 & & 0.794 & & & & \\
\hline MS2 & & 0.800 & & & & \\
\hline MS3 & & 0.849 & & & & \\
\hline MS4 & & 0.835 & & & & \\
\hline $\mathrm{MC} 1$ & & & 0.836 & & & \\
\hline MC2 & & & 0.869 & & & \\
\hline MC3 & & & 0.859 & & & \\
\hline MAD1 & & & & & & 0.731 \\
\hline MAD2 & & & & & & 0.707 \\
\hline MCB1 & 0.905 & & & & & \\
\hline MCB2 & 0.901 & & & & & \\
\hline MCB3 & 0.842 & & & & & \\
\hline MCB4 & 0.885 & & & & & \\
\hline MCB5 & 0.907 & & & & & \\
\hline
\end{tabular}

Table 4. Convergent and discriminant validity.

\begin{tabular}{cccccccccc}
\hline & CR & AVE & MSV & LERM & LSRM & MS & MC & MAD & MCB \\
\hline LERM & 0.888 & 0.725 & 0.328 & $\mathbf{0 . 8 5 2}$ & & & & & \\
LSRM & 0.870 & 0.769 & 0.514 & 0.499 & $\mathbf{0 . 8 7 7}$ & & & & \\
MS & 0.911 & 0.814 & 0.371 & 0.470 & 0.609 & $\mathbf{0 . 9 5 6}$ & & & \\
MC & 0.904 & 0.758 & 0.514 & 0.348 & 0.717 & 0.507 & $\mathbf{0 . 8 7 1}$ & & \\
MAD & 0.916 & 0.733 & 0.354 & 0.501 & 0.595 & 0.532 & 0.361 & $\mathbf{0 . 8 5 6}$ & \\
MCB & 0.888 & 0.726 & 0.352 & 0.573 & 0.593 & 0.495 & 0.383 & 0.584 & $\mathbf{0 . 8 5 2}$ \\
\hline
\end{tabular}

be more than 0.7 and 0.5 respectively, and in all of the cases above, it can be observed that all of the values of CR and AVE, against all of the variables are more than 0.7 and 0.5 , respectively. This represents the validity of the research model, moreover, the diagonal top values are representing the results for the discriminate validity, which should be more than $70 \%$, for all the variables it is more than $70 \%$, which means all of the variables have maximum loading with itself, this also proves the authenticity of the data that is collected. 


\subsection{Confirmatory Factor Analysis}

Table 5 is representing the results for the confirmatory factor analysis, it can be observed that all of the indicators have results in correspondence and alignment with the threshold values. The value of CMIN is 2.066 which is exactly within the threshold range that is less than or equal to 3. Moreover, in the case of GFI, the value is 0.917 , which is greater than 0.80 , the value of CFI is 0.978 , which is more than 0.90 and same is the case with IFI as well. Moreover, the value for RMSEA is equal to 0.054 , which is more than 0.08 , so the value for this indicator is valid as well.

\subsection{Structural Equation Modelling}

The results of the structural equation modelling are provided in Table 6, the impact of the Leader ethical role modelling on the morally courageous behaviour is insignificant, because the direct impact is insignificant. The impact of the leader safety role modelling on the morally courageous behaviour is significant

Table 5. Confirmatory factors analysis.

\begin{tabular}{ccc}
\hline Indicators & Threshold range & Current values \\
\hline CMIN/DF & Less or equal 3 & 2.066 \\
GFI & Equal or greater 0.80 & 0.917 \\
CFI & Equal or greater 0.90 & 0.978 \\
IFI & Equal or greater 0.90 & 0.978 \\
RMSEA & Less or equal 0.08 & 0.054 \\
\hline
\end{tabular}

Table 6. Structural equation modeling.

\begin{tabular}{|c|c|c|c|c|c|}
\hline Total Effect & LERM & LSRM & MS & MC & MAD \\
\hline MAD & $0.399^{* * *}$ & $0.224^{\star *}$ & 0.000 & 0.000 & 0.000 \\
\hline MC & $0.256^{\star *}$ & $0.177^{\star *}$ & 0.000 & 0.000 & 0.000 \\
\hline MS & $0.412^{\star * *}$ & $0.240^{\star *}$ & 0.000 & 0.000 & 0.000 \\
\hline MCB & $0.335^{\star * *}$ & $0.283^{\star * *}$ & $0.206^{\star *}$ & $0.232^{\star *}$ & $0.215^{\star *}$ \\
\hline Direct Effect & LERM & LSRM & MS & MC & MAD \\
\hline MAD & $0.399^{* * *}$ & $0.224^{\star *}$ & 0.000 & 0.000 & 0.000 \\
\hline MC & $0.256^{\star *}$ & $0.177^{\star *}$ & 0.000 & 0.000 & 0.000 \\
\hline MS & $0.412^{* * *}$ & $0.240^{\star *}$ & 0.000 & 0.000 & 0.000 \\
\hline MCB & 0.104 & $0.144^{\star *}$ & $0.206^{* *}$ & $0.232^{\star *}$ & $0.215^{\star *}$ \\
\hline Indirect Effect & LERM & LSRM & MS & $\mathrm{MC}$ & MAD \\
\hline MAD & 0.000 & 0.000 & 0.000 & 0.000 & 0.000 \\
\hline MC & 0.000 & 0.000 & 0.000 & 0.000 & 0.000 \\
\hline MS & 0.000 & 0.000 & 0.000 & 0.000 & 0.000 \\
\hline MCB & $0.230^{\star *}$ & $0.139^{* *}$ & 0.000 & 0.000 & 0.000 \\
\hline
\end{tabular}


and positive, and is equal to $14.4 \%$, which means that with $1 \%$ increase in the leader safety role modelling, morally courageous behaviour will enhance by 14.4\%. The mediation of moral sympathy between leader ethical role modelling and morally courageous behaviour is significant and positive because there is significant impact of the Leader ethical role modelling on the moral sympathy and in return, moral sympathy also significantly and positively impacts morally courageous behaviour, with a value equal to $20.6 \%$. On the other hand, the mediation of the moral sympathy between leader safety role modelling and morally courageous behaviour is significant and positive as well. The mediation of moral contempt between leader ethical role modelling and morally courageous behaviour is significant and positive as the leader ethical role modelling significantly and positively impact moral contempt by $25.6 \%$ and in return, moral contempt positively impacts morally courageous behaviour by $23 \%$. The mediation of moral contempt between leader safety role modelling and morally courageous behaviour is significant and positive as well, as leader safety role modelling significantly and positively impacts moral contempt by $17.7 \%$ and in return the moral contempt significantly and positively enhances morally courageous behaviour by $23.2 \%$. The mediation of moral anger and disgust is significant and positive between leader ethical role modelling and morally courageous behaviour as well, because the leader ethical role modelling impacts moral anger and disgust by $39.9 \%$ and as a result the mediator impacts morally courageous behaviour by $21.5 \%$ positively and significantly. In the same way, the mediation of the moral anger and disgust between leader safety role modelling and morally courageous behaviour is significant and positive as well. So, the only insignificant impact is of leader ethical role modelling on morally courageous behaviour. The screenshot of structural equation modelling is provided in Figure 2, it involves a part diagram that is representing the relationship present between

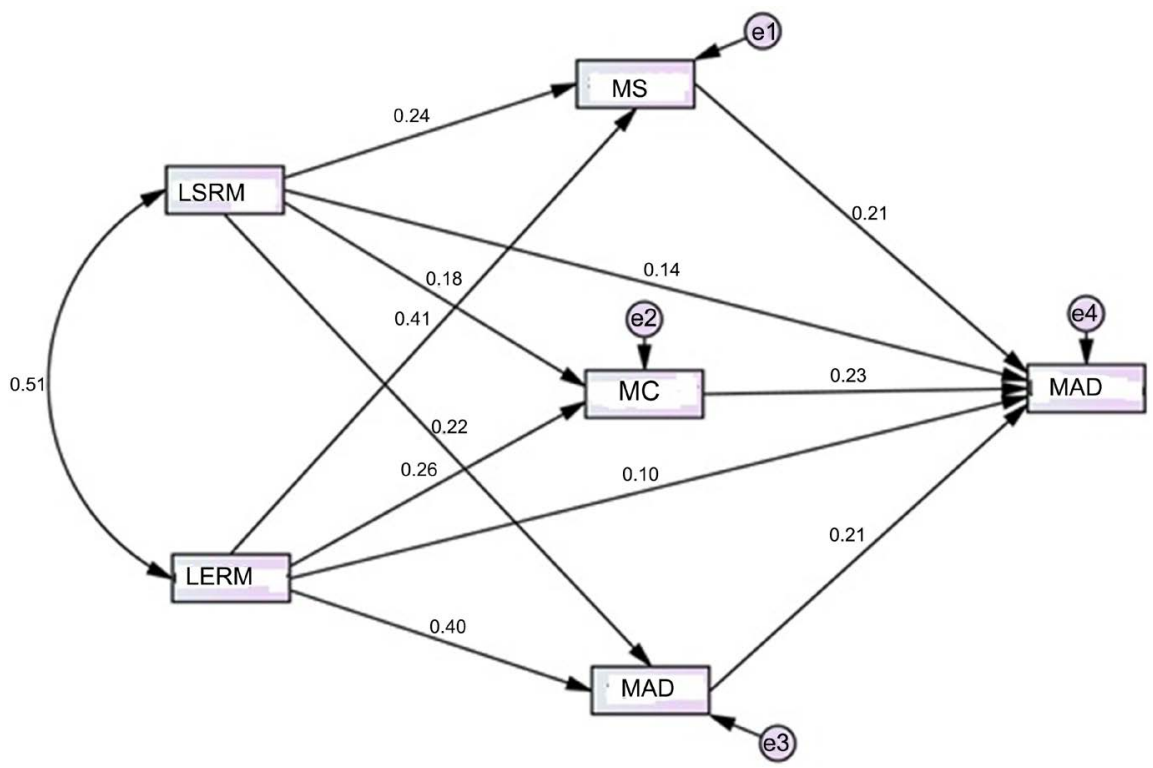

Figure 2. Structural equation modelling. 
the two dependent variables, three mediating variables and one dependent variable of the study.

\section{Discussion and Conclusion}

\subsection{Discussion}

The aims of this study include to find out the impact of leader ethical role modelling and leader safety role modelling on the morally courageous behavior; the study also assessed the mediation of moral sympathy, moral contempt and moral anger and disgust between the relationship of leader ethical role modelling formal leader safety role modelling and morally courageous behaviour. The first hypothesis "Leader ethical role modelling is significantly related to morally courageous behaviour among employees" is rejected by the results of this study, and the results resonate with the studies of (Tang, 2019; Xiao, Zhang, \& de Pablos, 2017; Zhang, Zheng, Cheng, \& Zhong, 2020). The second hypothesis, "Leader safety role modelling is significantly related to morally courageous behaviours among employees" has been accepted by the results of this study, and the studies of (Shaikh \& Siddiqui, 2020; Smith \& Kouchaki, 2021; Sosik, Chun, Ete, Arenas, \& Scherer, 2019) also propose that, the leader acts as a motivational role model for the employees because they follow his or her every practice in an organization so that he or she can get success in his career. Hypothesis three, four and five regarding the mediation of moral sympathy, moral contempt and moral anger and disgust in the relationship between leader ethical role modelling and morally courageous behaviour, have been accepted by the results of this study. Moreover, several studies propose it as well that, moral emotions are agent-driven or recipient driven as explained by a study for studying moral emotions as implications for employee's behaviour (Pietersen, 2018; Rai \& Banerjee, 2019; Rai \& Prakash, 2016). Moral emotions help to elevate prosocial behaviour among employees. These emotions are learned from past experiences, learning, and biologically (Hendriks, Burger, Rijsenbilt, Pleeging, \& Commandeur, 2020; Khan, Bauman, \& Javed, 2020; MacDougall, Bagdasarov, Johnson, \& Mumford, 2015). Leadership styles or behaviours are important in modelling the behaviour of the employee as they became a source of evoking moral emotions among employees (Feng, 2016; Godbless, 2021), it prepares the employees to behave courageously against the negative emotions of anger and disgust as anger is the feeling of displeasure having the varying adverse list of destructive consequences such as violence, aggression, bullying. The hypotheses six, seven and eight regarding the mediation of moral sympathy, moral contempt and moral anger and disgust in the relationship between Leader Safety Role Modelling and Morally Courageous Behaviour, have been accepted by the results of this study, and other studies propose as well that, supervisor or subordinate relationship is very crucial in creating a safe climate at the workplace (Amabile \& Pratt, 2016; Brender-Ilan \& Sheaffer, 2019). Several researchers have proposed that, leader role modelling relating to the safety of the employees in an organization will prove very benefi- 
cial because it will lead towards a high-quality exchange relationship among them (Shaikh \& Siddiqui, 2020; Smith \& Kouchaki, 2021).

\subsection{Conclusion}

The results of the study have proposed that the impact of leader safety role modeling on the morally courageous behavior is significant and positive, whereas the impact of leader ethical role modeling on the morally courageous behavior is found to be insignificant. Moreover, the mediation of moral sympathy, moral contempt and moral anger and disgust, in the relationship between leader ethical role modeling and morally courageous behavior, and in between the relationship of leader safety role modeling and morally courageous behavior has been found to be significantly positive as well.

\subsubsection{Implications of the Study}

The current study has significantly addressed and removed the gaps of the previous studies by explaining that how the different hurdles of the moral emotions can be controlled and managed by the leaders through the leader role modeling, so that the morally courageous behavior can be developed in the employees. In this study, it has been significantly identified that how both leader role model and moral emotions can be inculcated together for the purpose of positively enhancing the morally courageous behavior in the employees by minimizing the negative emotions at the workplace. The study also promotes the importance of the ethical conduct and social responsibilities of the leaders for promoting the morally courageous behavior in the employees at the workplace, that can positively and competitively enhance the outcomes of the workplace. Study has stressed over the duties and obligations that need to be fulfilled both from the side of the leaders and the employees, to maximize the organizational outcomes. So, the study has advanced the literature by considering the factors of moral sympathy, moral contempt and moral anger and disgust as mediators in the study. The propositions of the study are going to possibly lead to the enhancement of leader ethical role modeling and leader safety role modeling for enhanced level of morally courageous behavior among employees in an organization. With the enhancement of emotions of sympathy, contempt, and anger and disgust, the level of morally courageous behavior in the environment of organizations is bound to grow positively, enhancing the overall positive moral atmosphere of the organization. Contempt and sympathy are found to be significantly playing a role in the enhancement of morally courageous behavior within the organizations, so these can be a positive addition in the organizational environment, enhancing the overall organizational outcomes positively as well.

\subsubsection{Limitations of the Study and Future Research Recommendations}

The main limitation of the study is that the data has to be collected for this study through online sources and methods; however, this is because of the restrictions of the pandemic of COVID-19. So, the future researchers are recommended to 
consider collecting the data through self-administered questionnaire-based survey or one-on-one interviews. Moreover, future researchers are also recommended to consider the variables of Moral Ownership, and Felt Obligation, for further defining the importance of obligations from both of the sides of the leaders and the employees at the workplace, to maximize the organizational outcomes. This study has only considered mediators only, future researchers are also recommended to consider adding moderators in the model as well.

\section{Conflicts of Interest}

The authors declare no conflicts of interest regarding the publication of this paper.

\section{References}

Amabile, T. M., \& Pratt, M. G. (2016). The Dynamic Componential Model of Creativity and Innovation in Organizations: Making Progress, Making Meaning. Research in Organizational Behavior, 36, 157-183. https://doi.org/10.1016/j.riob.2016.10.001

Bandura, A. (1997). Social Learning Theory. Englewood Cliffs, NJ: Prentice Hall.

Blau, P. M. (1964). Justice in Social Exchange. Sociological Inquiry, 34, 193-206. https://doi.org/10.1111/j.1475-682X.1964.tb00583.x

Brender-Ilan, Y., \& Sheaffer, Z. (2019). How Do Self-Efficacy, Narcissism and Autonomy Mediate the Link between Destructive Leadership and Counterproductive Work Behaviour. Asia Pacific Management Review, 24, 212-222.

https://doi.org/10.1016/j.apmrv.2018.05.003

Brown, M. E., Treviño, L. K., \& Harrison, D. A. (2005). Ethical Leadership: A Social Learning Perspective for Construct Development and Testing. Organizational Behavior and Human Decision Processes, 97, 117-134. https://doi.org/10.1016/j.obhdp.2005.03.002

Clarke, S., \& Ward, K. (2006). The Role of Leader Influence Tactics and Safety Climate in Engaging Employees' Safety Participation. Risk Analysis, 26, 1175-1185. https://doi.org/10.1111/j.1539-6924.2006.00824.x

Crowley, J. P. (2013). Attributes of Highly Contemptuous People. Western Journal of Communication, 77, 340-360. https://doi.org/10.1080/10570314.2012.740763

De Jong, J., Clinton, M., Rigotti, T., \& Bernhard-Oettel, C. (2012). Nonlinear Associations between Breached Obligations and Employee Well-Being. Journal of Managerial Psychology, 30, 374-389. https://doi.org/10.5465/AMBPP.2012.14400abstract

Detert, J. R., \& Bruno, E. A. (2017). Workplace Courage: Review, Synthesis, and Future Agenda for a Complex Construct. Academy of Management Annals, 11, 593-639. https://doi.org/10.5465/annals.2015.0155

Feng, F.-I. (2016). School Principals' Authentic Leadership and Teachers' Psychological Capital: Teachers' Perspectives. International Education Studies, 9, 245-255. https://doi.org/10.5539/ies.v9n10p245

Ford, M. T., Agosta, J. P., Huang, J. Y., \& Shannon, C. (2017). Moral Emotions toward Others at Work and Implications for Employee Behavior: A Qualitative Analysis Using Critical Incidents. Journal of Business and Psychology, 33, 155-180.

Gabriel, Y., Lindebaum, D., \& Geddes, D. (2016). Moral Emotions and Ethics in Organisations: Introduction to the Special Issue. Journal of Business Ethics, 141, 645-656. 
Godbless, E. E. (2021). Moral Leadership, Shared Values, Employee Engagement, and Staff Job Performance in the University Value Chain. International Journal of Organizational Leadership, 10, 15-38.

Greenbaum, R., Bonner, J., Gray, T., \& Mawritz, M. (2019). Moral Emotions: A Review and Research Agenda for Management Scholarship. Journal of Organizational Behavior, 41, 95-114. https://doi.org/10.1002/job.2367

Haidt, J. (2003). The Moral Emotions. In R. J. Davidson, K. R. Scherer, \& H. H. Goldsmith (Eds.), Series in Affective Science. Handbook of Affective Sciences (pp. 852-870). Oxford: Oxford University Press.

Hair, J. F., Celsi, M., Ortinau, D. J., \& Bush, R. P. (2010). Essentials of Marketing Research (Vol. 2). New York: McGraw-Hill/Irwin.

Harvey, P., Martinko, M. J., \& Borkowski, N. (2016). Justifying Deviant Behavior: The Role of Attributions and Moral Emotions. Journal of Business Ethics, 141, 779-795. https://doi.org/10.1007/s10551-016-3046-5

Hendriks, M., Burger, M., Rijsenbilt, A., Pleeging, E., \& Commandeur, H. (2020). Virtuous Leadership and Employee Flourishing: The Mediating Role of Work Engagement. Manuscrito não publicado.

Huang, Y.-H. et al. (2016). Beyond Safety Outcomes: An Investigation of the Impact of Safety Climate on Job Satisfaction, Employee Engagement and Turnover Using Social Exchange Theory as the Theoretical Framework. Applied Ergonomics, 55, 248-257.

Huang, Y.-H. et al. (2021). Key Drivers of Trucking Safety Climate from the Perspective of Leader-Member Exchange: Bayesian Network Predictive Modeling Approach. Accident Analysis \& Prevention, 150, Article ID: 105850.

Hulin, C. L. (2002). Lessons from Industrial and Organizational Psychology. In J. M. Brett, \& F. Drasgow (Eds.), The Psychology of Work: Theoretically Based Empirical Research (pp. 3-22). Mahwah, NJ: Lawrence Erlbaum Associates Publishers.

Izard, C. E., Libero, D. Z., Putnam, P., \& Haynes, O. M. (1993). Stability of Emotion Experiences and Their Relations to Traits of Personality. Journal of Personality and Social Psychology, 64, 847-860.

Khan, S. R., Bauman, D. C., \& Javed, U. (2020). A Study on the Effect of Ethical Leadership on Teachers' Moral Motivation at Schools in Pakistan. International Journal of Educational Management, 34, 965-985. https://doi.org/10.1108/IJEM-06-2019-0198

Koerner, M. (2014). Courage as Identity Work: Accounts of Workplace Courage. The Academy of Management Journal, 57, 63-93. https://doi.org/10.5465/amj.2010.0641

Lindebaum, D., \& Geddes, D. (2016). The Place and Role of (Moral) Anger in Organizational Behavior Studies. Journal of Organizational Behavior, 37, 738-757. https://doi.org/10.1002/job.2065

Liu, D., Liao, H., \& Loi, R. (2012). The Dark Side of Leadership: A Three-Level Investigation of the Cascading Effect of Abusive Supervision on Employee Creativity. Academy of Management Journal, 55, 1187-1212.

MacDougall, A. E., Bagdasarov, Z., Johnson, J. F., \& Mumford, M. D. (2015). Managing Workplace Ethics: An Extended Conceptualization of Ethical Sense-Making and the Facilitative Role of Human Resources. In Research in Personnel and Human Resources Management (Research in Personnel and Human Resources Management, Vol. 33) (pp. 121-189). Bingley: Emerald Group Publishing Limited. https://doi.org/10.1108/S0742-730120150000033006

Maibom, H. L. (2009). Feeling for Others: Empathy, Sympathy, and Morality. Inquiry, 52, 483-499. https://doi.org/10.1080/00201740903302626 
Morgenroth, T., Ryan, M. K., \& Peters, K. (2015). The Motivational Theory of Role Modeling: How Role Models Influence Role Aspirants' Goals. Review of General Psychology, 19, 465-483. https://doi.org/10.1037/gpr0000059

Nasir, M., \& Bashir, A. (2012). Examining Workplace Deviance in Public Sector Organizations of Pakistan. International Journal of Social Economics, 39, 240-253.

https://doi.org/10.1108/03068291211205677

Ogunfowora, B. (2014). It's All a Matter of Consensus: Leader Role Modeling Strength as a Moderator of the Links between Ethical Leadership and Employee Outcomes. Human Relations, 67, 1467-1490. https://doi.org/10.1177/0018726714521646

Ogunfowora, B., Maerz, A., \& Varty, C. T. (2021). How Do Leaders Foster Morally Courageous Behavior in Employees? Leader Role Modeling, Moral Ownership, and Felt Obligation. Journal of Organizational Behavior, 42, 483-503.

https://doi.org/10.1002/job.2508

Osswald, S., Greitemeyer, T., Fischer, P., \& Frey, D. (2010). What Is Moral Courage? Definition, Explication and Classification of a Complex Construct. In C. Pury, \& S. Lopez (Eds.), Psychology of Courage (pp. 149-164). Washington DC: APA. https://doi.org/10.1037/12168-008

Pietersen, C. (2018). A Typology for the Categorisation of Ethical Leadership Research. African Journal of Business Ethics, 12, 54-69. https://doi.org/10.15249/12-2-153

Rai, H., \& Banerjee, B. (2019). The Role of Gender and Leader Tenure in the Relationship between Spirituality \& Ethical Leadership. Indian Journal of Industrial Relations, 54, 497-515.

Rai, R., \& Prakash, A. (2016). How Do Servant Leaders Ignite Absorptive Capacity? The Role of Epistemic Motivation and Organizational Support. Revista de Psicología del Trabajo y de las Organizaciones, 32, 123-134. https://doi.org/10.1016/j.rpto.2016.02.001

Rich, G. A. (1997). The Sales Manager as a Role Model: Effects on Trust, Job Satisfaction, and Performance of Salespeople. Journal of the Academy of Marketing Science, 25, 319-328. https://doi.org/10.1177/0092070397254004

Scott, P. A. (2001). Emotion, Moral Perception, and Nursing Practice. Nursing Philosophy, 1, 123-133.

Sekerka, L. E., Bagozzi, R. P., \& Charnigo, R. (2009). Facing Ethical Challenges in the Workplace: Conceptualizing and Measuring Professional Moral Courage. Journal of Business Ethics, 89, Article No. 565. https://doi.org/10.1007/s10551-008-0017-5

Shaikh, S., \& Siddiqui, D. A. (2020). How Moral Character Strengths Pay in Work: The Complementary Role of Self-Control and Self-Confidence in Influencing Ethical Leadership, That Consequently Affect Leader Outcomes.

https://doi.org/10.2139/ssrn.3756987

Shannon, C., Ford, M. T., Agosta, J. P., \& Huang, J. Y. (2018). Moral Emotions toward Others at Work and Implications for Employee Behavior: A Qualitative Analysis Using Critical Incidents. Journal of Business and Psychology, 33, 155-180.

Smith, I. H., \& Kouchaki, M. (2021). Ethical Learning: The Workplace as a Moral Laboratory for Character Development. Social Issues and Policy Review, 15, 277-322. https://doi.org/10.1111/sipr.12073

Sosik, J. J., Chun, J. U., Ete, Z., Arenas, F. J., \& Scherer, J. A. (2019). Self-Control Puts Character into Action: Examining How Leader Character Strengths and Ethical Leadership Relate to Leader Outcomes. Journal of Business Ethics, 160, 765-781. https://doi.org/10.1007/s10551-018-3908-0

Stange, J. (2019). Quantumn Workplace. https://www.quantumworkplace.com 
Steiger, R. L., \& Reyna, C. (2016). Trait Contempt, Anger, Disgust, and Moral Foundation Values. Personality and Individual Differences, 113, 125-135.

https://doi.org/10.1016/j.paid.2017.02.071

Syed, F. et al. (2019). When Leader Is Morally Corrupt: Interplay of Despotic Leadership and Self-Concordance on Moral Emotions and Bullying Behavior. Journal of Management Development, 39, 911-928.

Tang, K. N. (2019). Leadership Styles and Organizational Effectivenes. In Leadership and Change Management (pp. 11-25). Berlin: Springer. https://doi.org/10.1007/978-981-13-8902-3 2

Thornberg, R., Pozzoli, T., Gini, G., \& Jungert, T. (2016). Unique and Interactive Effects of Moral Emotions and Moral Disengagement on Bullying and Defending among School Children. The Elementary School Journal, 116, 322-337. https://doi.org/10.1086/683985

Tse, H. H. M. et al. (2018). Affect and Leader-Member Exchange in the New Millennium: A State-of-Art Review and Guiding Framework. Leadership Quarterly, 29, 135-149.

Xiao, Y., Zhang, X., \& de Pablos, P. O. (2017). How Does Individuals' Exchange Orientation Moderate the Relationship between Transformational Leadership and Knowledge Sharing? Journal of Knowledge Management, 21, 1622-1639.

https://doi.org/10.1108/JKM-03-2017-0120

Yasir, M., \& Rasli, A. (2018). Direct and Indirect Effects of Ethical Leadership on Workplace Deviance in Public Healthcare Sector of Pakistan. Journal of Advances in Management Research, 15, 558-574.

Zhang, Z., Zheng, J., Cheng, B., \& Zhong, J. (2020). Is a Mindful Worker More Attentive? The Role of Moral Self-Efficacy and Moral Disengagement. Ethics \& Behavior, 1-16. https://doi.org/10.1080/10508422.2020.1859376

Zohar, D., Huang, Y.-H., Lee, J., \& Robertson, M. (2014). A Mediation Model Linking Dispatcher Leadership and Work Ownership with Safety Climate as Predictors of Truck Driver Safety Performance. Accident Analysis \& Prevention, 62, 17-25.

https://doi.org/10.1016/j.aap.2013.09.005 